\title{
Distributive Implications of Fertility Changes in Latin America
}

\author{
Nicolás Badaracco, Leonardo Gasparini, and Mariana Marchionni \\ Centro de Estudios Distributivos, Laborales y Sociales (CEDLAS), Facultad de Ciencias Económicas, \\ Universidad Nacional de La Plata and CONICET, 1900 La Plata, Argentina \\ Correspondence should be addressed to Nicolás Badaracco; badaracconicolas@gmail.com
}

Received 13 February 2016; Accepted 22 May 2016

Academic Editor: Jonathan Haughton

Copyright ( 92016 Nicolás Badaracco et al. This is an open access article distributed under the Creative Commons Attribution License, which permits unrestricted use, distribution, and reproduction in any medium, provided the original work is properly cited.

Fertility rates significantly fell over the last decades in Latin America. In order to assess the extent to which these changes contributed to the observed reduction in income poverty and inequality, we apply microeconometric decomposition to microdata from national household surveys from seven Latin American countries. We find that changes in fertility rates were associated with a nonnegligible reduction in inequality and poverty in the region. The main channel was straightforward: lower fertility implied smaller families and hence larger per capita incomes. Lower fertility also fostered labor force participation, especially among women, which contributed to the reduction of poverty and inequality in most countries, although the size of this effect was smaller.

\section{Introduction}

Fertility rates have been significantly falling during the last decades in Latin America. The average number of children decreased in families from all population groups, but the decline was sharper among poor households: the fertility gap between the most and the least vulnerable groups shrunk in the region. The distributive impact of these demographic changes could be sizeable. Ceteris paribus, a fall in the number of children in poor households and in those marginally above the poverty line, reduces income poverty, whereas heterogeneous changes in family size across income groups could reduce income inequality.

In this paper, we assess the extent to which changes in fertility in seven Latin American countries (Argentina, Brazil, Chile, El Salvador, Mexico, Peru, and Uruguay) contributed to the observed reduction in income poverty and inequality during the 1990s and 2000s. To that aim, we simulate the counterfactual household per capita income distribution if fertility outcomes in a given year would have been determined as in another different year. The term fertility is used as a shortcut for the number of children in the household, which in most cases changes as a consequence of fertility decisions. Of course, actual changes in poverty and inequality are driven by various factors, including some of those affecting fertility. Estimating a general equilibrium model or complex structural equations that take into account all the interactions is not feasible, given lack of data, among other limitations. Instead, in this paper, we follow a more modest but potentially useful methodology: we compute the first-round partialequilibrium impact on the income distribution of changes in fertility. That impact could be taken as an approximation of the magnitude that fertility changes may have on poverty and inequality. In particular, we examine three effects: first, more children in the household imply a reduction in current per capita income, as a similar budget should be divided among more people; second, higher fertility may affect the intensive and extensive margins of labor supply among adults in the household; and, third, it may also affect the income transfers received through social programs targeted at families with children.

If we observe that family size declines for the poor more than for the rich, it is rather obvious that poverty and inequality measured over the distribution of household current income per capita will also decline. This paper makes two contributions to this intuition. First, it provides estimates of the magnitude of the direct distributive impact of the changes in fertility, that is, the extent to which the actual decline in poverty and inequality can be accounted for by only the change in the reproductive behavior. Second, the methodology allows tracing and measuring some not-soobvious effects. The fall in the number of children in the 
bottom strata of the distribution may induce some lowincome women to enter the labor market or to work more hours. In that case, the decline in poverty and inequality might be larger than expected if one only considers the direct impact of the decline in family size. In addition, a reduction in fertility may reduce the income transfers received by poor households in terms of social assistance directed to families with children.

In this paper, we find that the changes in fertility that took place over the last decades in Latin America contributed to the reduction in income inequality as well as in poverty. The fall in fertility among the income-deprived helped to reduce the incidence of income poverty. Besides, since it was larger than the fall among the nonpoor, it contributed to the reduction in income inequality, as well. The main channel was straightforward: lower fertility rates implied smaller families and hence larger per capita incomes. Lower fertility also fostered labor force participation, especially among women, which contributed to the reduction of poverty and inequality in most countries, although the size of this effect was small.

The rest of the paper is organized in a straightforward way. In the next section, we document changes in fertility across income groups and present trends in income inequality and poverty in Latin America. In Section 3, we lay out the methodology, discuss its limitations, and introduce the data used in the estimations. Section 4 presents the main results of the paper, whereas Section 5 closes with some concluding remarks.

\section{Fertility Changes and Distributive Trends}

In the early 1960s, the total fertility rate (TFR) was around 6 children per woman in Latin America, higher than the world's average (total fertility rate is the average number of children a hypothetical cohort of women would have at the end of their reproductive period if, during their whole lives, they were subject to the fertility rates of a given period and if they were not subject to mortality; it is expressed as children per woman (United Nations, World Population Prospects: The 2012 Revision, definition available at http://esa.un.org/wpp/Excel-Data/fertility.htm)). It was not until the mid-1960s that TFR began its downward trend, which eventually led to clear convergence towards the levels of the most advanced regions of the world (Figure 1). In particular, the TFR continued falling over the last two decades in Latin America, reaching an average of 2.5 children per woman in 2005-2010 (this decreasing trend has been present in developed countries since the beginning of the past century $[1,2]$. For an analysis of fertility dynamics in Latin America, see Chackiel [3] and ECLAC [4,5].

Following a similar trend, the number of children per household (the proxy for fertility that can be implemented with household survey microdata) has been falling over the last two decades. In 1992, there were 2.3 children under the age of 16 per household (for households with a woman aged 25-45) in a typical Latin American country; the figure was 1.8 in 2012 [6].

The average number of children decreased in households from all population groups, but the gap between the most

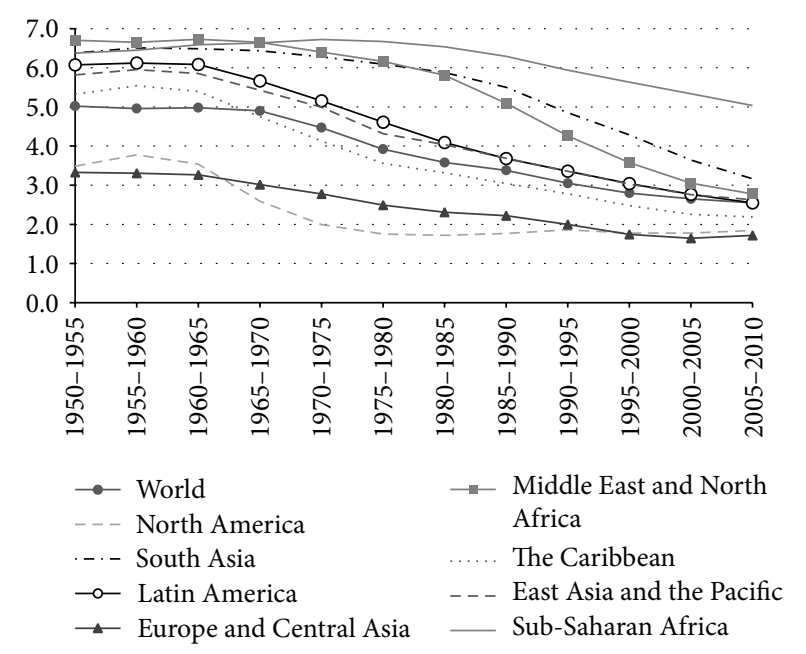

FIGURE 1: Total fertility rate (children per woman). Regions of the world, 1950-2010. Source: Gasparini and Marchionni [6], based on World Population Prospects: The 2012 Revision, DVD Edition.

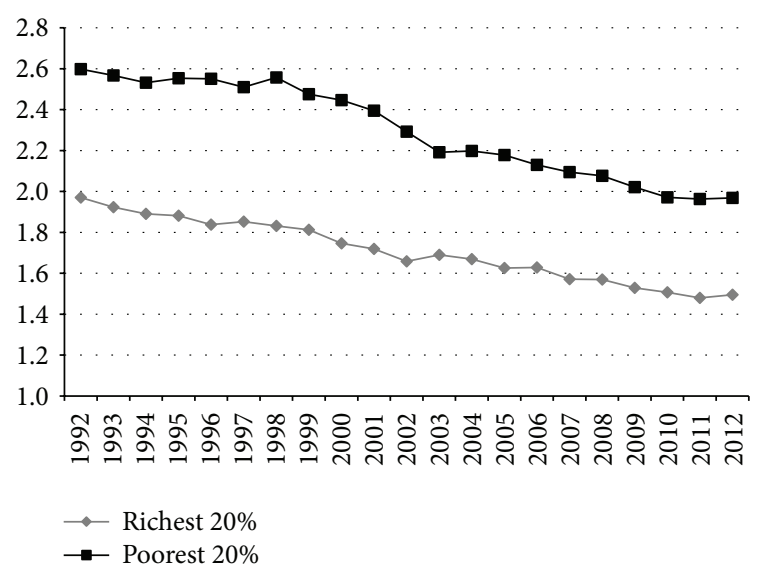

FIgURE 2: Number of children under 16 per household. Bottom and top quintiles of parental income distribution, 1992-2012. Source: own calculations based on microdata from national household surveys. Note: average of seven Latin American countries: Argentina, Brazil, Chile, El Salvador, Mexico, Peru, and Uruguay. Households with head aged 25-45. Unweighted means.

and the least vulnerable groups shrank, owing to a sharper decline in the number of children living in poor households. Figure 2 takes a sample of seven Latin American countries to show the average number of children under 16 per household in the poorest $20 \%$ and richest $20 \%$ of the prime-age parents (the sample includes countries in which we implement the microsimulations that follow in the next section). In both groups, fertility went down over the two decades; the fall is somewhat more pronounced among the poorest couples. The gap in the number of children per household shrank from 0.67 in 1992 to 0.47 in 2012.

With regard to the income distribution, Latin America experienced an increase in inequality during the 1990s, while poverty slightly decreased [7-9]. In contrast, in the 2000s, there were strong reductions of both income inequality and 

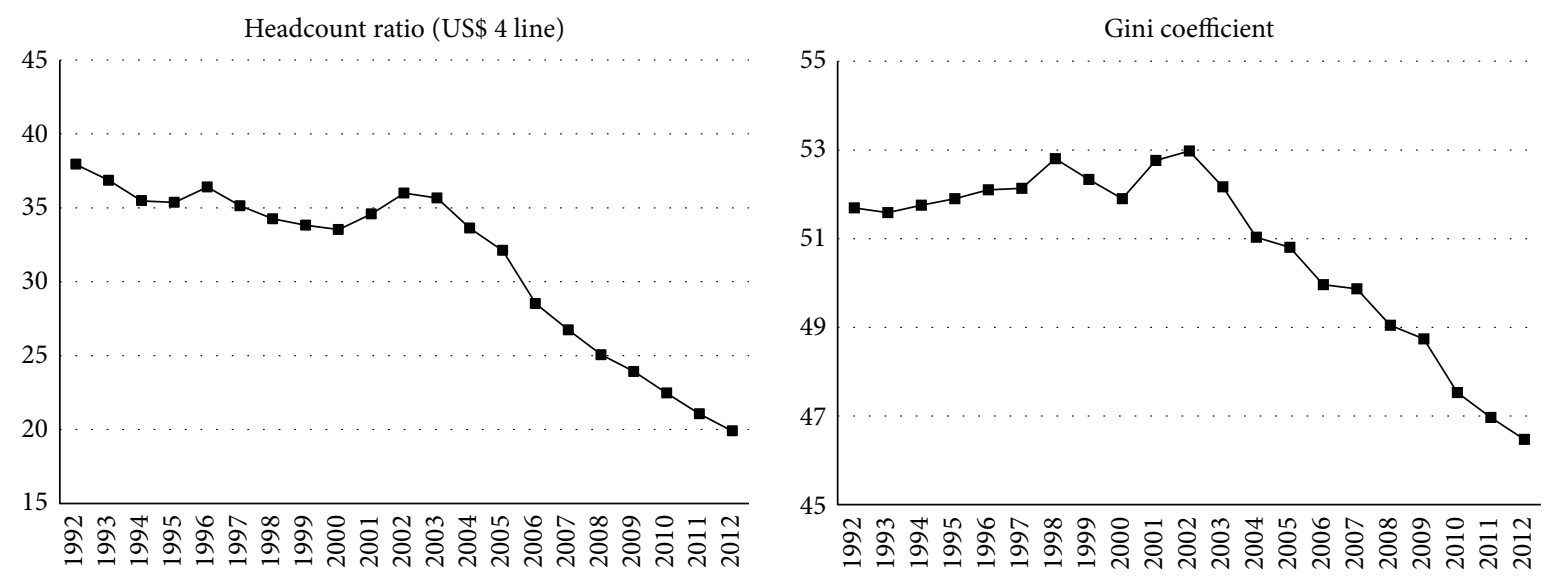

FIgURE 3: Poverty and income inequality: Latin America. Source: own calculations based on microdata from national household surveys. Note: average of seven Latin American countries: Argentina, Brazil, Chile, El Salvador, Mexico, Peru, and Uruguay. Unweighted means. Poverty and inequality computed over the distribution of household per capita income.

poverty. Figure 3 shows the average income inequality and poverty trends of seven Latin American countries. Poverty is measured by the headcount ratio with a daily US\$ 4 line, while income inequality is measured by the Gini coefficient. Both indices are calculated over the household per capita income distribution. Income poverty slightly decreased during the 1990s and fell sharply during the 2000s. Argentina, Uruguay, and Mexico suffered an increase in poverty during the 1990s and then a continuous fall over the following decade (Figure 4). Meanwhile, Brazil, Chile, El Salvador, and Peru experienced a decrease in poverty over the entire period, though steeper during the 2000s.

On average, for our sample of seven countries, income inequality increased during the first decade under analysis and then significantly decreased during the 2000s. The trend for the 1990s is driven by the sharp increase in income dispersion in Argentina and Uruguay (Figure 5) and the small changes in the rest of the countries. In contrast, during the 2000 s, the fall in inequality was strong and generalized to all economies.

\section{Data and Methodology}

We focus on seven Latin American countries, Argentina, Brazil, Chile, El Salvador, Mexico, Peru, and Uruguay, during the 1990s and 2000s. The analysis is based on microdata from national household surveys collected by the corresponding National Statistical Offices. Table 1 presents a brief description of these databases. Since surveys are not homogeneous, we have made all possible efforts to make variables comparable across countries and over time by using similar definitions of variables in each country/year and by applying consistent methods of processing the data.

The ideal variable for capturing fertility would be the number of children, either living in the household or not. Unfortunately, this variable is usually not available in Latin American household surveys, with the exception of Brazil. As a proxy, we use the number of children living in the household. Consequently, two main problems emerge. First,
TABLE 1: Household surveys.

\begin{tabular}{lccc}
\hline Country & Survey & Acronym & Years \\
\hline Argentina & $\begin{array}{c}\text { Encuesta Permanente de } \\
\text { Hogares }\end{array}$ & EPH & 1992-2012 \\
Brazil & $\begin{array}{c}\text { Pesquisa Nacional por } \\
\text { Amostra de Domicilios } \\
\text { Encuesta de }\end{array}$ & PNAD & 1990-2012 \\
Chile & $\begin{array}{c}\text { Caracterización } \\
\text { El Salvador } \\
\text { Socioeconómica Nacional } \\
\text { Encuesta de Hogares de } \\
\text { Propósitos Múltiples }\end{array}$ & EHPM & $1991-2010$ \\
& $\begin{array}{c}\text { Encuesta Nacional de } \\
\text { Ingresos y Gasto de los } \\
\text { Hexico }\end{array}$ & ENIGH & $1990-2011$ \\
Peru & $\begin{array}{c}\text { Encuesta Nacional de } \\
\text { Hogares }\end{array}$ & ENAHO & $1997-2012$ \\
Uruguay & $\begin{array}{c}\text { Encuesta Continua de } \\
\text { Hogares }\end{array}$ & ECH & $1995-2012$ \\
\hline
\end{tabular}

the measurement error of this proxy depends on the age of parents and children; that is, on average, the older the parents and the older the children are, the more likely they leave the parental home. Therefore, the observed differences in the number of children across households are not only due to reproductive decisions, but also due to the life cycle. To deal with this shortcoming, we restrict our sample to households where the head of household is between 25 and 45 years old. Many people below 25 years old may not have yet started childbearing. The average age at childbearing for the countries under analysis was 27.5 years in 1993 and 27.6 years in 2011. The dispersion across countries is also small, ranging from 26.5 in Mexico to 28.3 in Peru. The average age at marriage in the early 1990s was 22.9 and 25.6 years for women and men, respectively, and about two years more in the early 2010s (25.0 and 27.5).

Another problem arises since Latin American household surveys usually register family relationships among 

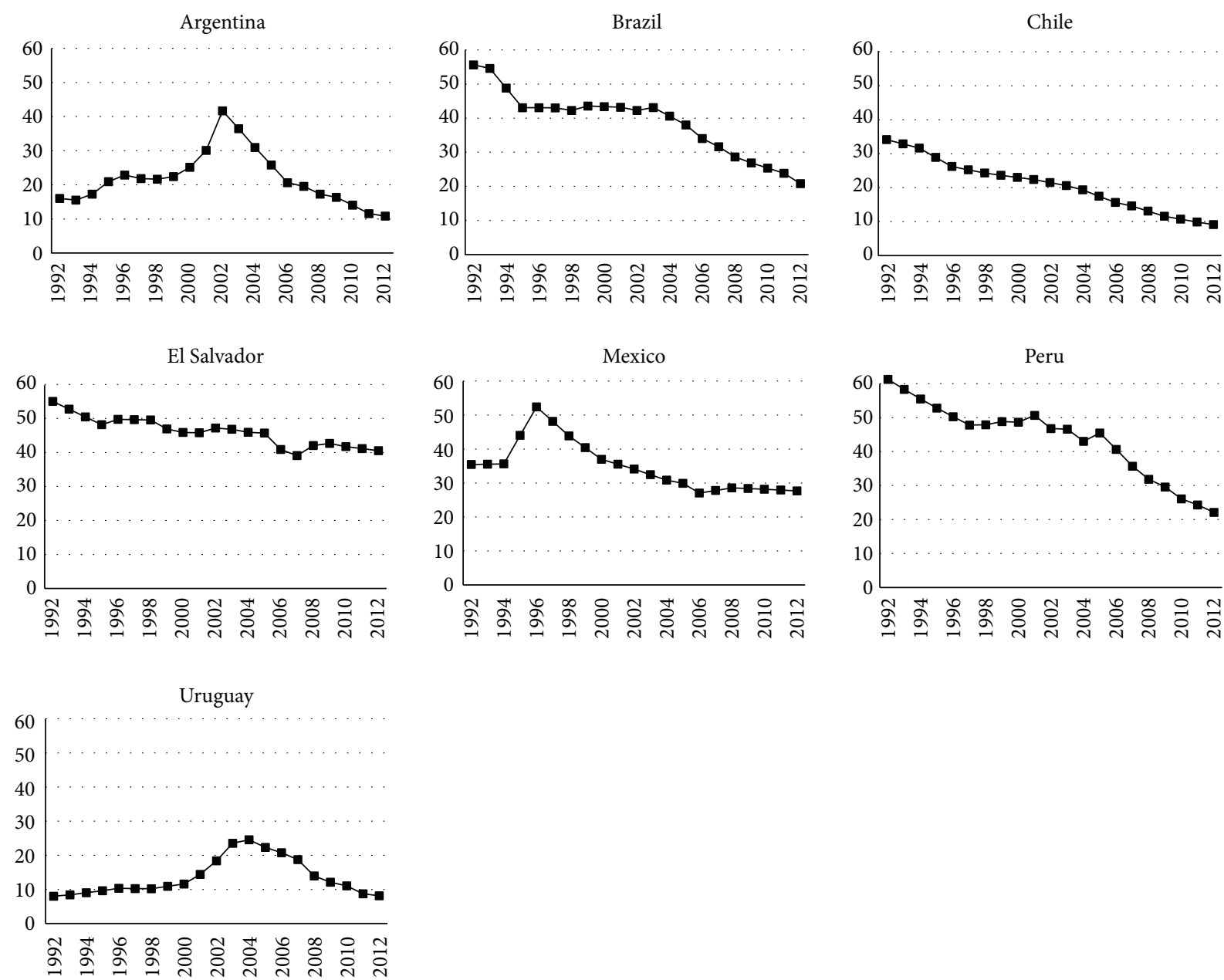

FIgURE 4: Poverty. Headcount ratio (US\$ 4 line). Source: own calculations based on microdata from national household surveys. Note: poverty computed over the distribution of household per capita income.

household members only in terms of the head of household; that is, it is possible to match children with their parents only when they are the head of household or the spouse. Therefore, we further restrict the analysis to only consider fertility decisions of the head of household and the spouse.

Regarding the empirical specification and estimation methodology, we follow Marchionni and Gasparini [10]. The main inputs to carry out the microsimulations are the estimates of the parameters that govern fertility decisions/outcomes (for simplicity, we refer to fertility decisions, although fertility outcomes could be the result of free conscious choices, but also the consequence of various other circumstances) and the response of labor market participation to changes in family size. We assume that the number of children in a household follows a Poisson process and that its parameters can be consistently estimated using a Poisson regression model. Hourly wages and hours of work are assumed to be simultaneously determined in an equilibrium model of the labor market.

After estimating the parameters, we carry out the simulations. That is, we simulate the counterfactual income distribution that arises in a given base year by assuming that the population in that year takes fertility decisions according to the parameters estimated for a different year. The resulting poverty and inequality measures over the simulated distribution are compared to those actually observed in the base year. The difference between the simulated value of an indicator of poverty or inequality and its actual value is interpreted as a measure of the direct impact of the change in fertility behavior, that is, the impact that would take place in case all other covariates remained fixed.

The methodology requires keeping all other things constant when simulating the impact of changes in fertility decisions. Naturally, as it was stressed in previous sections, some of these factors may be correlated with fertility. For instance, the structure of wages may respond to changes in the labor supply triggered by a change in fertility. Additionally, changes in reproductive behavior may have been induced by income changes, in which case the microsimulation only captures a single round of effects, from fertility to incomes, of a more complicated process.

In a given period, income poverty and inequality are affected by a host of factors, including economic shocks and social policies. The microsimulation methodology is useful as it allows approximating the size of the impact that a given factor would have, in case all other factors remained 

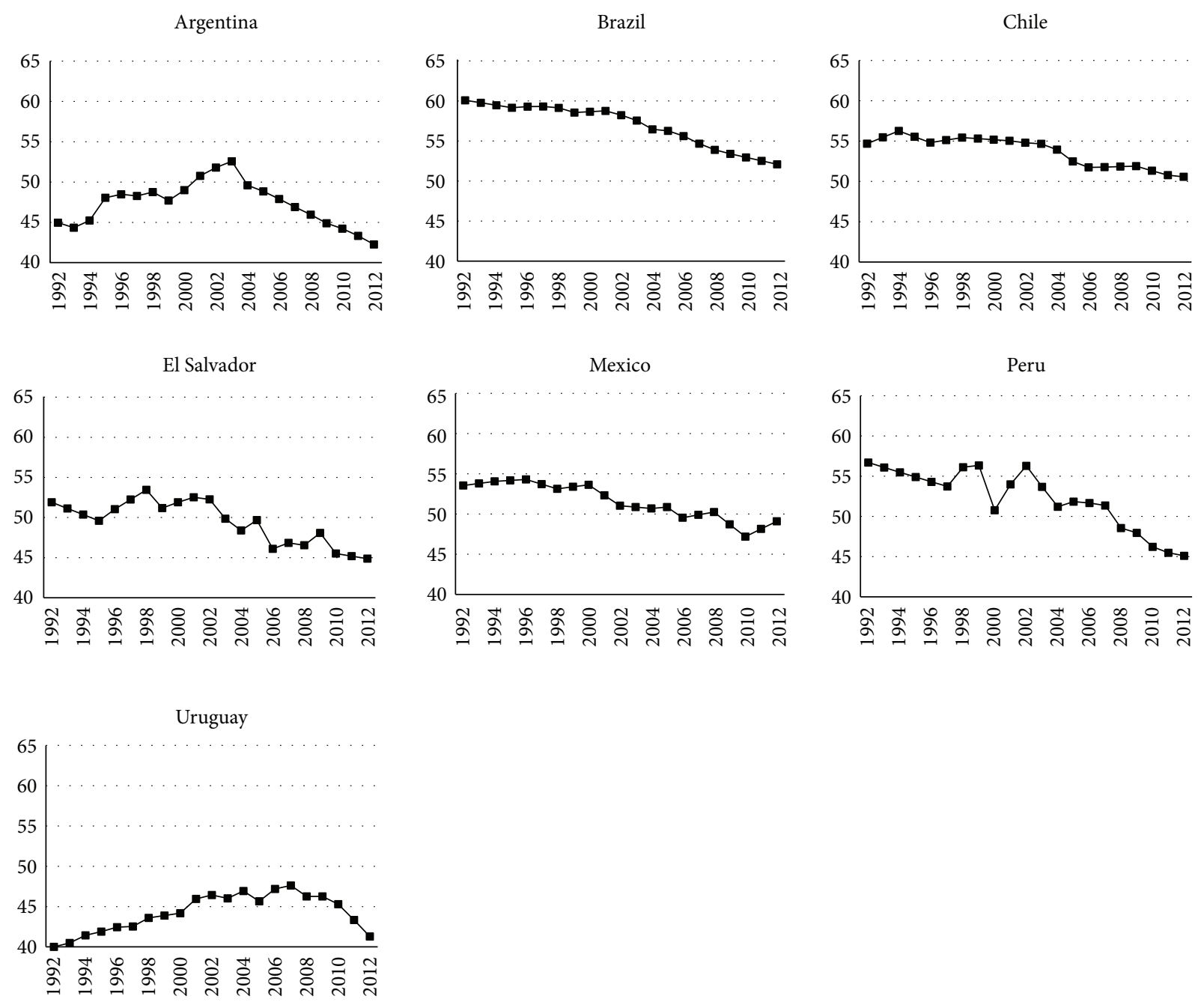

Figure 5: Income inequality. Gini coefficient. Source: own calculations based on microdata from national household surveys. Note: inequality computed over the distribution of household per capita income.

fixed. Although this is clearly an unrealistic scenario, the estimations are still useful as a first approximation of the impact, especially considering the fact that the more ambitious alternative of estimating a general equilibrium model is usually unfeasible.

3.1. Microsimulations. We carry out the simulation over the distribution of household per capita income, defined as

$$
y_{i t}=\frac{Y_{h t}^{L}+Y_{h t}^{N L}}{N_{h t}} \quad \forall i \in h \text { at time } t,
$$

where $i$ indexes individuals, $h$ households, and $t$ time periods (years). $Y_{h t}^{L}$ denotes total labor income of household $h$ at time $t, Y_{h t}^{N L}$ labels nonlabor income, and $N_{h t}$ is the family size, which is the sum of the number of children up to 16 years old $H_{h t}$ and the rest of the household members $R_{h t}$ :

$$
N_{h t}=H_{h t}+R_{h t} .
$$

We need to specify how $H_{h t}$ is determined in order to simulate the counterfactual distributions. The literature argues that fertility outcomes are the result of a process affected by characteristics of each spouse and of the household, among other factors. This process can be formalized as

$$
H_{h t}=H\left(Z_{h t}, e_{h t} ; \eta_{t}\right)
$$

where $Z_{h t}$ is a vector of observable characteristics and $e_{h t}$ includes all unobservable characteristics that influence the family's reproductive behavior, while $\eta_{t}$ is the set of parameters that govern fertility decisions.

We assume that labor income for individual $i$ is given by

$$
Y_{i t}^{L}=w_{i t} L_{i t},
$$

where $w_{i t}$ is the hourly wage rate and $L_{i t}$ is the number of hours worked by individual $i$. Wages and hours of work are defined as $w_{i t}=w\left(X_{1 i t}, \varepsilon_{i t}^{W} ; \beta_{t}\right)$ and $L_{i t}=$ $L\left(X_{2 i t}, H_{i t}, \varepsilon_{i t}^{L} ; \gamma_{t}, \lambda_{t}\right)$, respectively. Where $X_{1 i t}$ and $X_{2 i t}$ are observable characteristics, $\varepsilon_{i t}^{W}$ and $\varepsilon_{i t}^{L}$ are unobservable characteristics, while $\beta_{t}, \gamma_{t}$, and $\lambda_{t}$ are parameters. In particular, $\lambda_{t}$ is the parameter that relates the hours of work to the number of children. 
Nonlabor income is usually assumed to be exogenous in the microsimulation literature. However, as stated in previous sections, the expansion of social programs to families with children suggests a potential link between fertility decisions and nonlabor income. Accordingly, we assume that nonlabor income is given by

$$
Y_{h t}^{N L}=m_{h t}+g\left(H_{h t}\right)
$$

where $m_{h t}$ is exogenous and $g\left(H_{h t}\right)$ represents the component of nonlabor income that depends on the number of children.

We label the parameters of the fertility decisions at time $t$ as $\eta_{t}$ and those at time $t^{\prime}$ as $\eta_{t^{\prime}}$. A key step in the methodology is to estimate the counterfactual number of children in a given year $t$ if fertility outcomes were determined as in an alternative year $t^{\prime}$. Once this term, labeled as $H_{h t}\left(\eta_{t^{\prime}}\right)$, is estimated, three microsimulation exercises are carried out by replacing this estimate in the household per capita income equation.

The first exercise aims to capture the contribution of the change in fertility parameters $\eta$ to the actual change in the income distribution through the denominator of (1). The simulated per capita income is given by

$$
y_{i t}^{D}=\frac{Y_{h t}^{L}+Y_{h t}^{N L}}{N_{h t}\left(\eta_{t^{\prime}}\right)}
$$

where $N_{h t}\left(\eta_{t^{\prime}}\right)=R_{h t}+H_{h t}\left(\eta_{t^{\prime}}\right)$. Superscript $D$ in the simulated per capita income stands for the direct-size effect, that is, the change in the income distribution due to changes in the number of household members among whom total household income should be distributed.

The second exercise involves simulating the labor income that a household would have in year $t$ if parameters that govern fertility decisions were those of year $t^{\prime}$. In other words, the exercise consists in replacing the simulated number of children $H_{h t}\left(\eta_{t^{\prime}}\right)$ in the equation of individual labor income (4), to obtain

$$
y_{i t}^{H}=\frac{Y_{h t}^{L}\left(\eta_{t^{\prime}}\right)+Y_{h t}^{N L}}{N_{h t}} .
$$

Superscript $H$ in the simulated per capita income stands for the hours-size effect, that is, the contribution of the change in fertility parameters $\eta$ to the actual change in the income distribution through the indirect channel of affecting the hours-of-work decisions.

We carry out a third exercise by simulating the counterfactual distribution arising from a change in nonlabor income driven by changes in fertility decisions. We refer to the distributional impact of changes through this channel as the nonlabor-income effect and thus label the per capita income variable in (8) with the $N L$ superscript:

$$
y_{i t}^{N L}=\frac{Y_{h t}^{L}+Y_{h t}^{N L}\left(\eta_{t^{\prime}}\right)}{N_{h t}} .
$$

Finally, (9) considers the three channels simultaneously to obtain the total effect (superscript $T$ ) of changes in the fertility parameters:

$$
y_{i t}^{T}=\frac{Y_{h t}^{L}\left(\eta_{t^{\prime}}\right)+Y_{h t}^{N L}\left(\eta_{t^{\prime}}\right)}{N_{h t}\left(\eta_{t^{\prime}}\right)} .
$$

We denote the per capita income distribution among individuals in year $t$ as $D_{t}\left(y_{t}\right)=\left(y_{1 t}, y_{2 t}, \ldots, y_{n t}\right)$, where $n$ denotes the total number of individuals in the population. Let $I(\cdot)$ be a distributive indicator, as the Gini coefficient or the poverty headcount ratio. Then, the contribution of the change in fertility parameters $\eta$ to the actual change in the income distribution through the direct channel is given by (10). The contributions through the other channels are computed analogously:

$$
I\left(D_{t}\left(y_{t}\right)\right)-I\left(D_{t}\left(y_{t}^{D}\right)\right) \text {. }
$$

A shortcoming of the microsimulation methodology is that decomposition is path-dependent. This means that taking year $t$ or year $t^{\prime}$ as the base year does not necessarily imply the same result. Accordingly, we perform the simulations alternating the base year and report the average effect for each exercise.

In the following subsections, we provide details concerning the specification and estimation of fertility, labor income, and nonlabor-income equations.

3.2. Fertility Decisions. We assume that the number of children in (3) follows a Poisson process with parameter $\mu_{h t}$. Formally,

$$
H_{h t} \sim \operatorname{Poisson}\left(\mu_{h t}\right) \quad \text { with } \mu_{h t}=E\left(H_{h t} \mid Z_{h t}\right)=\exp \left(Z_{h t}^{\prime} \eta_{t}\right) .
$$

Then,

$$
\operatorname{Prob}\left(H_{h t}=H_{0}\right)=\frac{\exp \left(-\mu_{h t}\right)\left(\mu_{h t}\right)^{H_{0}}}{H_{0} !} \text { with } H_{0}=0,1,2, \ldots
$$

Equation (12) is the Poisson regression model, from which it is possible to consistently estimate parameters $\eta_{t}$ by maximum likelihood (it can be shown that consistency holds for the maximum likelihood estimators of $\eta_{t}$ as long as the real distribution is any of the linear exponential family, to which the Poisson distribution belongs, provided that the conditional mean in (11) is correctly specified; see, e.g., Wooldridge [11]). We estimate separate models for two-parent household and single-parent households. For simplicity, we denote the estimates by $\eta$.

Once parameters $\eta$ are estimated, we proceed to simulate changes in the number of children. Since the objective is to simulate these changes as a consequence of changes only in the parameters $\eta$, it is necessary to keep unobservable factors fixed. Therefore, we characterize each household by the quantile it occupies in the distribution of children of year $t$. Let $F_{\eta_{t} \mid Z_{h t}}(\cdot)$ be the cumulative probability function of a random variable that follows a Poisson distribution with parameter equal to $\exp \left(Z_{h t}^{\prime} \eta_{t}\right)$ and let $q_{h t}$ be the quantile for household $h$ at time $t$; that is, $F_{\eta_{t} \mid Z_{h t}}\left(H_{h t}\right)=q_{h t}$. The 
simulated number of children in household $h$ will be the one that places it in the $q_{h t}$ quantile of the distribution of children with the relevant parameters of time $t^{\prime}\left(\eta_{t^{\prime}}\right)$ conditional to the observable characteristics $Z_{h t}$. Formally, the simulated number of children in household $h$ at year $t$ using the estimated fertility parameters for year $t^{\prime}$ is given by

$$
H_{h t}\left(\eta_{t^{\prime}}\right)=F_{\eta_{t^{\prime}} \mid Z_{h t}}^{-1} \circ F_{\eta_{t} \mid Z_{h t}}\left(H_{h t}\right) \text {. }
$$

3.3. Labor Incomes. To estimate individual labor income in (4), we follow Gasparini et al. [12] in assuming that both wages and hours worked are determined in a reduced-form model of the labor market equilibrium:

$$
\begin{gathered}
\ln w_{i t}^{*}=X_{1 i t}^{\prime} \beta_{t}+\varepsilon_{i t}^{W}, \\
L_{i t}^{*}=X_{2 i t}^{\prime} \gamma_{t}+H_{i t} \lambda_{t}+\varepsilon_{i t}^{L},
\end{gathered}
$$

with

$$
\begin{gathered}
\text { if } L_{i t}^{*}>0, \\
w_{i t}=w_{i t}^{*}, \\
L_{i t}=L_{i t}^{*} \\
\text { if } L_{i t}^{*} \leq 0, \\
w_{i t}=0, \\
L_{i t}=0 \\
\left(\varepsilon_{i t}^{W}, \varepsilon_{i t}^{L}\right) \sim N\left(0,0, \sigma_{W t}^{2}, \sigma_{L t}^{2}, \rho_{t}\right),
\end{gathered}
$$

where $w_{i t}^{*}$ and $L_{i t}^{*}$ are unobserved latent variables. Vectors $X_{1 i t}$ and $X_{2 i t}$ include observable factors affecting hourly wages and hours of work, respectively, while $H_{i t}$ stands for the number of children. $\beta_{t}, \gamma_{t}$ (vectors), and $\lambda_{t}$ are parameters to be estimated, along with $\sigma_{W t}^{2}, \sigma_{L t}^{2}$, and $\rho_{t}$.

We estimate (14) by Heckman's maximum likelihood method, where a censored version of (15) is used as a selection equation replacing hours of work by a binary variable that indicates whether the individual works. For estimation of (15), we use a Tobit model (although this estimation strategy is not fully efficient, efficiency loss is not necessarily significant for a given sample size and this alternative has certain computational advantages over a full information procedure; for more details, see Gasparini et al. [12]). We estimate separate models for head of households and spouses.

To simulate changes in individual labor incomes, we replace the observed number of children of individual $i$ at year $t$ in (15) by the simulated number of children $H_{t h}\left(\eta_{t^{\prime}}\right)$, while assigning him/her a wage based on (14), and an error term drawn from the bivariate distribution implicit in the model.

3.4. Nonlabor Incomes. The measure of nonlabor income includes pensions, capital income, and transfers. Conditional cash transfers are included as government transfers. We simulate nonlabor incomes in an ad hoc manner, taking into account the characteristics of each country's social program. In those cases, where it is not possible to identify the recipients in the household survey, we identify potential beneficiaries and estimate the amount of the transfers based on the design of each program. The general framework is as follows: nonlabor income of household $h$ at year $t$ is given by (5), where $g\left(H_{h t}\right)$ represents the part of nonlabor income that depends on the number of children. Typically, cash transfers in poverty-alleviation programs vary with the number of children in the family. For example, if the program has a fixed amount $\theta_{t}$ per child, the nonlabor income becomes

$$
Y_{h t}^{N L}=m_{h t}+\theta_{t} H_{h t} .
$$

The simulated nonlabor income is calculated using the counterfactual number of children in a given year $t$ if fertility outcomes were determined as in an alternative year $t^{\prime}$ :

$$
Y_{h t}^{N L}\left(\eta_{t^{\prime}}\right)=m_{h t}+\theta_{h t} H_{h t}\left(\eta_{t^{\prime}}\right) \text {. }
$$

Even though all programs have a similar setting to the one described, they differ in some aspects: maximum number of children, age, and in some cases how to identify the program's recipients. The details are given in the Appendix. We simulate nonlabor incomes for Argentina, Brazil, Mexico, and Uruguay. Even though the programs in Chile, El Salvador, and Peru have similar characteristics, it is not possible to estimate how the amount of transfers varies with the number of children given the information in the household surveys. For these countries, we assume that nonlabor income is completely exogenous.

\section{The Results}

The results of the microsimulations regarding poverty are presented in Table 2. Column (i) displays the observed change in the headcount ratio, while the rest of the columns present the impact of the changes in fertility on poverty. Column (v) shows the sum of all effects explored. In order to better understand the information in the table, take the case of Brazil as an example. Column (i) shows that between 1990 and 2012 the poverty headcount ratio in that country (using the line of US\$ 4 a day) fell by around 25 points. The value in the last column has the following interpretation: if fertility had been the only factor that changed during that period, then the poverty headcount ratio in Brazil would have fallen by 3.92 points. This change is statistically significant, although not very big compared to the actual fall in poverty in that period. The overall effect is the result of a significant direct effect $(-3.74)$ and two smaller effects that go in different directions. On the one hand, the differential reduction in fertility implied a greater increase in hours of work among more disadvantaged households, which in turn contributed, though very slightly, to a further reduction in income poverty. On the other hand, the falling patterns in fertility among the poor ameliorated the poverty-decreasing impact of the conditional cash transfer programs that are targeted at families with children (mainly the Bolsa Familia in the 2000s). However, this effect was quantitatively almost insignificant. 
TABLE 2: Impact of fertility changes on poverty. Changes in the poverty headcount ratio (US\$ 4 line).

\begin{tabular}{|c|c|c|c|c|c|c|}
\hline \multirow{2}{*}{ Country } & \multirow{2}{*}{ Period } & \multirow{2}{*}{ Observed change (i) } & \multicolumn{4}{|c|}{ Effects } \\
\hline & & & Direct (ii) & Hours (iii) & NLI (iv) & Total (v) \\
\hline \multirow{2}{*}{ Argentina } & \multirow{2}{*}{$1992-2012$} & -11.22 & -1.39 & 0.04 & 0.39 & -0.80 \\
\hline & & $(0.08)$ & $(0.02)$ & $(0.01)$ & $(0.01)$ & $(0.02)$ \\
\hline \multirow{2}{*}{ Brazil } & \multirow{2}{*}{ 1990-2012 } & -25.16 & -3.74 & -0.17 & 0.14 & -3.92 \\
\hline & & $(0.03)$ & $(0.01)$ & $(0.00)$ & $(0.00)$ & $(0.01)$ \\
\hline \multirow{2}{*}{ Chile } & \multirow{2}{*}{ 1990-2011 } & -33.24 & -1.56 & 0.18 & - & -1.43 \\
\hline & & $(0.05)$ & $(0.01)$ & $(0.00)$ & - & $(0.01)$ \\
\hline \multirow{2}{*}{ El Salvador } & \multirow{2}{*}{ 1991-2010 } & -14.12 & -4.98 & -0.34 & - & -5.31 \\
\hline & & $(0.06)$ & $(0.04)$ & $(0.01)$ & - & $(0.05)$ \\
\hline \multirow{2}{*}{ Mexico } & \multirow{2}{*}{$1992-2012$} & -3.50 & -4.35 & -0.30 & 0.25 & -4.43 \\
\hline & & $(0.10)$ & $(0.04)$ & $(0.02)$ & $(0.01)$ & $(0.04)$ \\
\hline \multirow{2}{*}{ Peru } & \multirow{2}{*}{$1997-2012$} & -23.20 & -3.83 & -0.19 & - & -3.94 \\
\hline & & $(0.09)$ & $(0.03)$ & $(0.01)$ & - & $(0.03)$ \\
\hline \multirow{2}{*}{ Uruguay } & \multirow{2}{*}{ 1995-2012 } & -1.56 & -0.08 & 0.00 & 0.02 & -0.05 \\
\hline & & $(0.03)$ & $(0.02)$ & $(0.00)$ & $(0.00)$ & $(0.02)$ \\
\hline
\end{tabular}

Source: own calculations based on microdata from national household surveys.

Note. All effects are significant at the $1 \%$ level. The standard errors were calculated using bootstrap with 200 replications. The values of each effect are averages that result from taking alternatively each year in the comparison as the base year. The sample includes only households in which the head is between 25 and 45 years old. NLI: nonlabor income.

TABLE 3: Impact of fertility changes on inequality. Changes in the Gini coefficient.

\begin{tabular}{|c|c|c|c|c|c|c|}
\hline \multirow{2}{*}{ Country } & \multirow{2}{*}{ Period } & \multirow{2}{*}{ Observed change (i) } & \multicolumn{4}{|c|}{ Effects } \\
\hline & & & Direct (ii) & Hours (iii) & NLI (iv) & Total (v) \\
\hline \multirow{2}{*}{ Argentina } & \multirow{2}{*}{$1992-2012$} & -5.44 & -1.04 & -0.01 & 0.13 & -0.95 \\
\hline & & $(0.10)$ & $(0.01)$ & $(0.00)$ & $(0.00)$ & $(0.02)$ \\
\hline \multirow{2}{*}{ Brazil } & \multirow{2}{*}{ 1990-2012 } & -7.18 & -1.30 & -0.06 & 0.06 & -1.32 \\
\hline & & $(0.04)$ & $(0.00)$ & $(0.00)$ & $(0.00)$ & $(0.00)$ \\
\hline \multirow{2}{*}{ Chile } & \multirow{2}{*}{ 1990-2011 } & -1.78 & -0.75 & 0.04 & - & -0.73 \\
\hline & & $(0.08)$ & $(0.01)$ & $(0.00)$ & - & $(0.01)$ \\
\hline \multirow{2}{*}{ El Salvador } & \multirow{2}{*}{ 1991-2010 } & -7.68 & -1.30 & -0.07 & - & -1.40 \\
\hline & & $(0.06)$ & $(0.02)$ & $(0.00)$ & - & $(0.02)$ \\
\hline \multirow{2}{*}{ Mexico } & \multirow{2}{*}{$1992-2012$} & -0.86 & -1.68 & -0.11 & 0.12 & -1.69 \\
\hline & & $(0.19)$ & $(0.02)$ & $(0.00)$ & $(0.00)$ & $(0.02)$ \\
\hline \multirow{2}{*}{ Peru } & \multirow{2}{*}{$1997-2012$} & -7.32 & -1.92 & -0.06 & - & -1.99 \\
\hline & & $(0.13)$ & $(0.01)$ & $(0.00)$ & - & $(0.01)$ \\
\hline \multirow{2}{*}{ Uruguay } & \multirow{2}{*}{$1995-2012$} & -2.03 & -0.12 & -0.01 & 0.02 & -0.13 \\
\hline & & $(0.04)$ & $(0.01)$ & $(0.00)$ & $(0.00)$ & $(0.01)$ \\
\hline
\end{tabular}

Source: own calculations based on microdata from national household surveys.

Note. All effects are significant at the $1 \%$ level. The standard errors were calculated using bootstrap with 200 replications. The values of each effect are averages that result from taking alternatively each year in the comparison as the base year. The sample includes only households in which the head is between 25 and 45 years old. NLI: nonlabor income.

Changes in fertility patterns over the last two decades in Latin America have implied a reduction in income poverty. The impact is statistically significant and in some cases economically large. For instance, the estimated povertyreduction effect was more than 4 points in Mexico and El Salvador. Most of the effect comes through the direct effect: a reduction in fertility rates among the most disadvantaged groups reduced family size and increased per capita income. The hours-of-work effect is in most cases poverty reducing and the nonlabor-income effect is poverty increasing, but in both cases the estimated sizes are small.

Table 3 shows the results of the simulations on income inequality, measured by the Gini coefficient. Inequality in Brazil, as measured by the Gini coefficient, fell by 7.18 points between 1990 and 2012. If fertility had been the only factor that changed in that period, then the Gini coefficient would have fallen by 1.32 points (column v). This change is statistically significant, representing around $18 \%$ of the actual reduction in inequality during that period. The differential 
reduction in fertility across socioeconomic groups in Brazil contributed to the observed decline in inequality in the last two decades. The overall effect of -1.32 points in column (v) is the result of a significant direct effect $(-1.30)$ and two smaller effects going in different directions.

Some interesting general results emerge from Table 3. First, changes in fertility have implied a decline in income inequality. The differential pattern in fertility across groups experienced in most Latin American countries over the last decades translated into an equalizing impact on the income distribution. Second, this effect is small, although not negligible. To be sure, demographic changes are not the central reason behind changes in income inequality but they are statistically significant and economically relevant. On average, fertility changes account for a fall of around one point in the Gini coefficient.

Third, most of the impact comes from the direct effect. The differential fall in fertility rates among socioeconomic groups had a larger impact on the family size of poorer families, implying a proportionally larger increasing effect on their per capita incomes.

Fourth, the effect of fertility changes on hours of work and, in turn, on incomes is smaller and has different signs across countries. It is important to notice that a more intense reduction in fertility among the poor may be consistent with a positive sign (inequality-increasing) for this effect. This could happen if the elasticity of hours of work with respect to the number of children is higher among the nonpoor and if the extra hours worked triggered by the fall in fertility imply a household income increase proportionally larger for the nonpoor. Anyway, with one exception, the hours-of-work effect has a negative sign, implying that the asymmetric reduction in fertility contributed to a reduction in income inequality by fostering higher participation in the labor market among poor parents (mostly mothers).

Finally, the effect through nonlabor incomes is always inequality-increasing, but small. The fall in fertility among the poor implied a lower inequality-reducing impact of the conditional cash transfer programs that were introduced and expanded in the region, mainly during the 2000s. The effect, however, is in most cases very small.

\section{Concluding Remarks}

Poverty and inequality fell in Latin America over the last decades, driven by a large number of factors. In this paper, we highlight one factor that is usually overlooked in the economic literature: the impact of changes in fertility. The average number of children fell in households from all groups, but especially among the more vulnerable, a fact that could have distributive implications. We quantify the consequences of this demographic pattern by applying microsimulation techniques. The results suggest that changes in fertility that took place over the last decades in Latin America contributed to the reduction in income inequality as well as in poverty. The impacts found were in general statistically significant and economically relevant, although not very large. Although surely there are more important determinants behind the observed patterns in the income distributions of the Latin American countries, demographic factors should not be overlooked.

The paper has focused on three simple yet central channels: the change in the number of children (i) enlarges the family size and reduces per capita income, (ii) affects the labor supply decisions, and (iii) modifies the income support from social programs. Certainly, there are other potentially relevant channels that are ignored in the paper. For instance, a reduction in the number of children per family could imply higher inheritances and higher family spending on education and health per child and, hence, better income perspectives. Also, smaller families may be better positioned to take advantage of labor market opportunities, for instance, through migration. Moreover, lower fertility rates may be associated with a reduction in the relative supply of unskilled labor and, hence, an increase in its relative wage.

Although, in the short and medium run, lower fertility in more disadvantaged households may contribute to reducing poverty and inequality, in the long run, the implications are more nuanced. When children become adults, they may contribute to their parents' incomes: a fall in fertility may reduce incomes for the elderly, especially in countries where the pension system is weak, and ultimately contribute to higher poverty through that intertemporal channel.

\section{Appendix}

In this appendix, we describe the issues regarding the simulations of the nonlabor incomes for each country.

\section{A. Argentina: Asignación Universal por Hijo (AUH)}

Argentina launched the conditional cash transfer program AUH in 2009. The beneficiaries are children under the age of 18 in households whose members are unemployed or informal workers. The program provides a monthly cash subsidy per child, up to 5 children. Since Argentina's household survey $(\mathrm{EPH})$ does not include a question to identify recipients of this program, we follow Garganta and Gasparini [13], assuming full take-up among those who qualify. The simulation is made according to the following rule:

$$
\begin{gathered}
\text { If } H_{h t}\left(\eta_{t^{\prime}}\right)+Q_{h t} \leq 5 \text { and } H_{h t}+Q_{h t} \leq 5, \\
Y_{h t}^{N L}\left(\eta_{t^{\prime}}\right)=Y_{h t}^{N L}+\theta_{t}\left(H_{h t}\left(\eta_{t^{\prime}}\right)-H_{h t}\right) . \\
\text { If } H_{h t}\left(\eta_{t^{\prime}}\right)+Q_{h t}>5 \text { and } H_{h t}+Q_{h t} \leq 5, \\
Y_{h t}^{N L}\left(\eta_{t^{\prime}}\right)=Y_{h t}^{N L}+\theta_{t}\left(5-H_{h t}-Q_{h t}\right) . \\
\text { If } H_{h t}\left(\eta_{t^{\prime}}\right)+Q_{h t} \leq 5 \text { and } H_{h t}+Q_{h t}>5, \\
Y_{h t}^{N L}\left(\eta_{t^{\prime}}\right)=Y_{h t}^{N L}+\theta_{t}\left(H_{h t}\left(\eta_{t^{\prime}}\right)+Q_{h t}-5\right) . \\
\text { If } H_{h t}\left(\eta_{t^{\prime}}\right)+Q_{h t}>5 \text { and } H_{h t}+Q_{h t}>5, \\
Y_{h t}^{N L}\left(\eta_{t^{\prime}}\right)=Y_{h t}^{N L},
\end{gathered}
$$


where $Q_{h t}$ is the number of children aged 17 or 18 (recall that we carry out the simulations for children aged 16 or younger) and $\theta_{t}$ is equal to $\operatorname{AR} \$ 270$ for the third trimester of 2012 and AR $\$ 340$ for the fourth trimester.

\section{B. Brazil: Bolsa Familia Program (BFP)}

The Bolsa Familia, implemented in 2003, is the flagship conditional cash transfer program in Brazil, aimed at poor households. The estimated nonlabor incomes in this case are calculated as follows:

$$
\begin{aligned}
& \text { If } H_{t h}>0 \text { and beneficiary, } \\
& \qquad Y_{h t}^{N L}\left(\eta_{t^{\prime}}\right)=Y_{t h}^{N L}+M_{t h}\left(\frac{H_{t h}\left(\eta_{t^{\prime}}\right)}{H_{t h}}-1\right) . \\
& \text { If } H_{t h}=0, H_{t h}\left(\eta_{t^{\prime}}\right)=k \text { and beneficiary, } \\
& \qquad Y_{h t}^{N L}\left(\eta_{t^{\prime}}\right)=Y_{t h}^{N L}+\bar{M}_{t h}^{k}-l_{t h},
\end{aligned}
$$

with $k=1,2,3, \ldots, M_{t h}$ being the amount of the transfer, $\bar{M}_{t h}^{k}$ being the average benefit of households with $k$ children, and $l_{t h}$ being the standard benefit of recipients without children.

\section{Mexico: Oportunidades}

Oportunidades is the main antipoverty program of the Mexican Government. The size of the transfer depends on the number of children, among other characteristics of the household. Mexico's ENIGH identifies the beneficiaries of the program and the amount of the subsidy that each household receives. The simulation is made as follows:

$$
\begin{aligned}
Y_{h t}^{N L}\left(\eta_{t^{\prime}}\right) & =Y_{t h}^{N L}+\bar{M}_{t h}^{k}-M_{t h}, \\
& \text { if } H_{t h}\left(\eta_{t^{\prime}}\right)=k, H_{t h} \neq k \text { and beneficiary, }
\end{aligned}
$$

where $\bar{M}_{t h}^{k}$ is the average transfer of a beneficiary household with $k$ children and $M_{t h}$ is the original household transfer.

\section{Uruguay: Asignaciones Familiares}

The Asignaciones Familiares program in Uruguay is targeted at the children of workers. The amount of the transfer varies with the household's income. Since the size of the transfer depends on characteristics of the child, such as the age, the simulation is carried out as follows:

$$
\begin{aligned}
& \text { If } H_{t h}>0 \text { and beneficiary, } \\
& \qquad Y_{h t}^{N L}\left(\eta_{t^{\prime}}\right)=Y_{t h}^{N L}+M_{t h}\left(\frac{H_{t h}\left(\eta_{t^{\prime}}\right)}{H_{t h}}-1\right) . \\
& \text { If } H_{t h}=0, H_{t h}\left(\eta_{t^{\prime}}\right)=k \text { and beneficiary, } \\
& \qquad Y_{h t}^{N L}\left(\eta_{t^{\prime}}\right)=Y_{t h}^{N L}+\bar{M}_{t h}^{k},
\end{aligned}
$$

with $k=1,2,3, \ldots, M_{t h}$ being the total amount of the transfer and $\bar{M}_{t h}^{k}$ being the average transfer of a household with $k$ children.

\section{Disclosure}

The information presented herein is solely the responsibility of the authors and does not necessarily reflect the opinions of the aforementioned entities.

\section{Competing Interests}

The authors declare that they have no competing interests.

\section{Acknowledgments}

This paper was written in the framework of the project Enhancing Women's Economic Empowerment through Better Policies in Latin America, a joint initiative between CEDLAS-UNLP and CIEDUR with the support of IDRC, Canada. The paper includes material from Nicolás Badaracco's Masters dissertation at Universidad Nacional de La Plata. The authors are grateful to Carolina Robino, Guillermo Cruces, Jorge Paz, Facundo Albornoz, and seminar participants at AAEP (Posadas, 2014), Network of Inequality and Poverty (UNGS, 2014), and Conference on Social Protection (IDRC and IPC, Brasilia, 2014) for valuable comments and suggestions.

\section{References}

[1] T. W. Guinnane, "The historical fertility transition: a guide for economists," Journal of Economic Literature, vol. 49, no. 3, pp. 589-614, 2011.

[2] L. E. Jones and M. Tertilt, "An economic history of fertility in the U.S.: 1826-1960,” NBER Working Paper 12796, 2006.

[3] J. Chackiel, La Dinámica Demográfica en América Latina, Serie Población y Desarrollo No. 52, Centro Latinoamericano y Caribeño de Demografía-División de Población de CEPAL, 2004.

[4] ECLAC, "La fecundidad en América Latina: un descenso acelerado y heterogéneo con profundas transformaciones demográficas y sociales," in Fertility, Latin American and the Caribbean Demographic Observatory, no. 5, Centro Latinoamericano y Caribeño de Demografía-División de Población de CEPAL, 2008.

[5] ECLAC, "Chapter II: current situation and outlook for fertility in Latin America," in Social Panorama of Latin America 2011, ECLAC, 2011.

[6] L. Gasparini and M. Marchionni, Bridging Gender Gaps? The Rise and Deceleration of Female Labor Force Participation, CEDLAS-UNLP, 2015.

[7] L. Gasparini and N. Lustig, "The rise and fall of income inequality in Latin America," in The Oxford Handbook of Latin American Economics, J. Ocampo and J. Ros, Eds., chapter 27, pp. 691-714, Oxford University Press, Oxford, UK, 2011.

[8] G. Cornia, Ed., Falling Inequality in Latin America. Policy Changes and Lessons, Oxford University Press, 2014. 
[9] F. Alvaredo and L. Gasparini, "Recent trends in inequality and poverty in developing countries," in Handbook of Income Distribution, Atkinson and Bourguignon, Eds., vol. 2, chapter 9, pp. 697-805, Elsevier, New York, NY, USA, 2015.

[10] M. Marchionni and L. Gasparini, "Tracing out the effects of demographic changes on the income distribution. The case of Greater Buenos Aires, 1980-1998," Journal of Economic Inequality, vol. 5, no. 1, pp. 97-114, 2007.

[11] J. M. Wooldridge, Econometric Analysis of Cross Section and Panel Data, MIT Press, Boston, Mass, USA, 2002.

[12] L. Gasparini, M. Marchionni, and W. Sosa Escudero, "Characterization of inequality changes through microeconometric decompositions. The case of Greater Buenos Aires," in The Microeconomics of Income Distribution Dynamics in East Asia and Latina America, F. Bourguignon, F. Ferreira, and N. Lustig, Eds., Oxford University Press, New York, NY, USA, 2004.

[13] S. Garganta and L. Gasparini, "The impact of a social program on labor informality: the case of AUH in Argentina," Journal of Development Economics, vol. 115, pp. 99-110, 2015. 


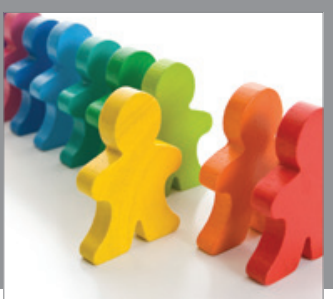

Autism

Research and Treatment
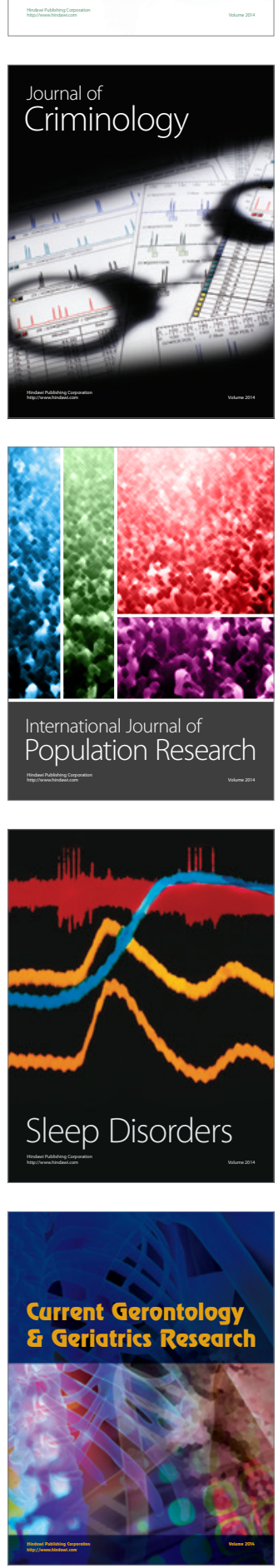

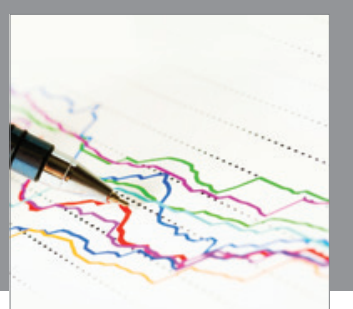

Economics

Research International
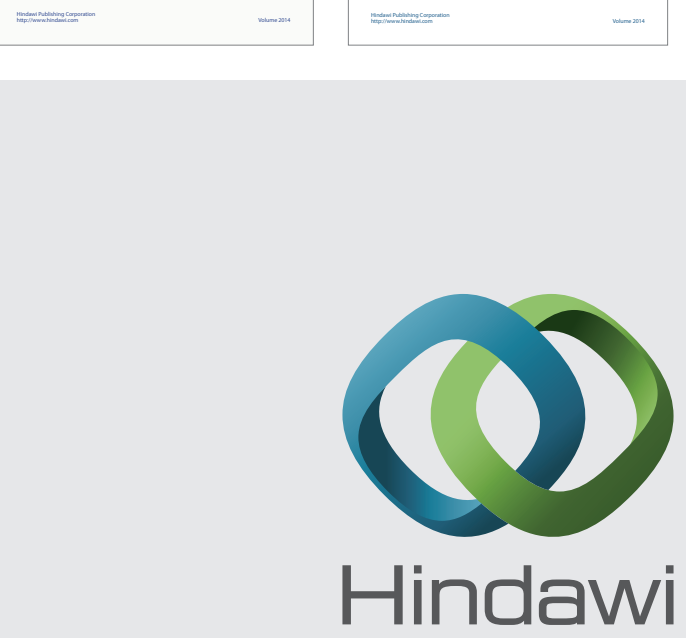

Submit your manuscripts at

http://www.hindawi.com
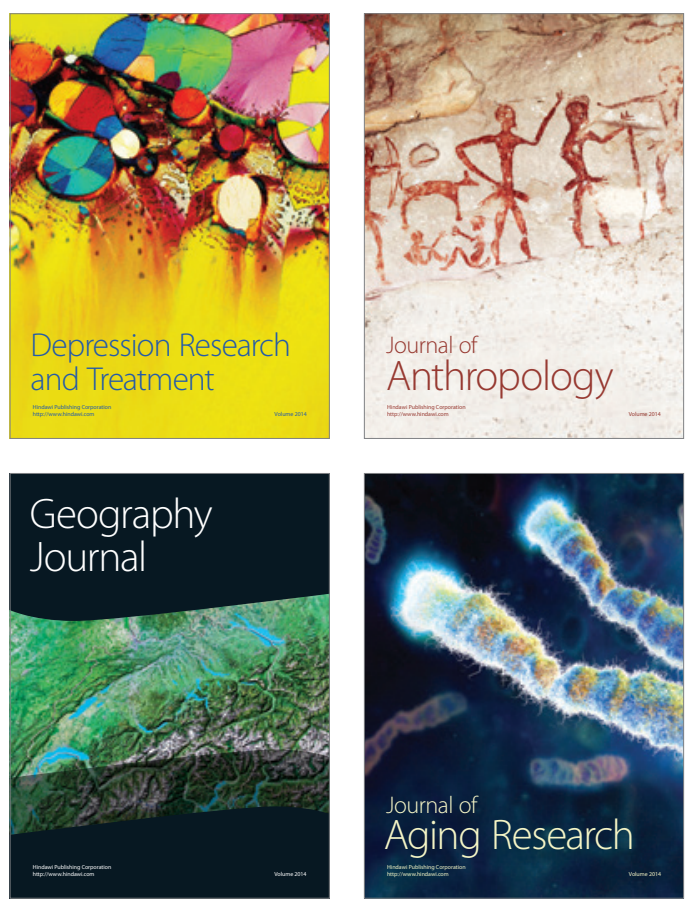
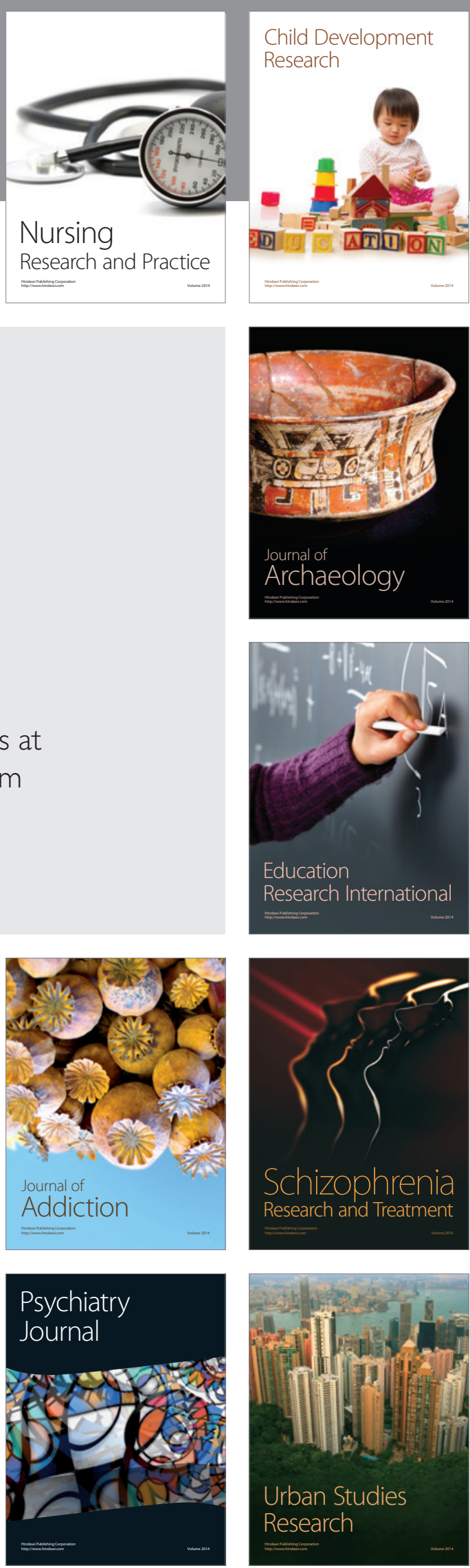